\title{
COMPARATIVE STUDY TO EVALUATE THE EFFECTS OF INTRANASAL DEXMEDETOMIDINE VERSUS MIDAZOLAM AS A PREMEDICATION AGENT IN CHILDREN UNDERGOING ELECTIVE SURGERY
}

Gurusamy Sivakumar1, Krishnamurthi Anitha², Pachaimuthu Elango ${ }^{3}$, Vivekanandan Balasubramaniaguhan ${ }^{4}$, Anbu Srinivasan $^{5}$

${ }^{1}$ Associate Professor, Department of Anaesthesiology, KAP Viswanatham Government Medical College/MGM Government Hospital, Trichy.

${ }^{2}$ Assistant Professor, Department of Anaesthesiology, KAP Viswanatham Government Medical College/MGM Government Hospital,

Trichy.

${ }^{3}$ Professor, Department of Anaesthesiology, KAP Viswanatham Government Medical College/MGM Government Hospital, Trichy.

${ }^{4}$ Assistant Professor, Department of Anaesthesiology, KAP Viswanatham Government Medical College/MGM Government Hospital,

Trichy.

${ }^{5}$ Associate Professor, Department of Orthopaedics, KAP Viswanatham Government Medical College/MGM Government Hospital, Trichy.

\section{ABSTRACT}

\section{BACKGROUND}

Intranasal route of drug administration is a practical option as a non-invasive alternative to intravenous route especially for children. We conducted a study to compare the effects of Dexmedetomidine and Midazolam administered as premedication agents through intranasal route. The primary outcome measures were assessing the sedation status upon parental separation and behaviour level during induction. The secondary outcome measures were assessing the acceptance of intravenous cannulation and acceptance of facemask during induction.

\section{MATERIALS AND METHODS}

Hundred children aged between 5-12 years of both sexes belonging to ASA grade I and II and weighing $<30 \mathrm{~kg}$ were enrolled in this prospective randomised double blinded study. The children were divided into two groups of 50 each. 60 minutes before induction, Group IN-D $(\mathrm{n}=50)$ received Intranasal Dexmedetomidine $1 \mu \mathrm{g} / \mathrm{kg}$ and Group IN-M $(\mathrm{n}=50)$ received Intranasal Midazolam $0.2 \mathrm{mg} / \mathrm{kg}$.

\section{RESULTS}

Sedation status at parental separation produced by dexmedetomidine is statistically significant when compared to midazolam. Both the drugs produced similar behaviour level inside the operating room, acceptance of IV cannulation and acceptance of facemask during induction.

\section{CONCLUSION}

Intranasal dexmedetomidine can be used as a preanaesthetic medication in children undergoing elective surgeries under general anaesthesia.

\section{KEYWORDS}

Anaesthesia, Premedication, Intranasal, Dexmedetomidine, Midazolam.

HOW TO CITE THIS ARTICLE: Sivakumar G, Anitha K, Elango P, et al. Comparative study to evaluate the effects of intranasal dexmedetomidine versus midazolam as a premedication agent in children undergoing elective surgery. J. Evolution Med. Dent. Sci. 2017;6(35):2893-2897, DOI: 10.14260/Jemds/2017/624

\section{BACKGROUND \\ Preoperative anxiety is a subjective feeling of worry, tension, apprehension and nervousness. In children, it is attributed to separation from parents. ${ }^{1}$ It largely affects the smoothness of induction, emergence from anaesthesia and also the psychological and emotional state of children in the remote future. ${ }^{2}$ A smooth transition from an awake state to surgical anaesthesia in children becomes a challenge for all anaesthesiologists. Eliminating or minimising stress provides a smooth atraumatic induction of anaesthesia. Preoperative \\ Financial or Other, Competing Interest: None. \\ Submission 01-03-2017, Peer Review 16-04-2017, \\ Acceptance 22-04-2017, Published 01-05-2017. \\ Corresponding Author: \\ Dr. Krishnamurthi Anitha, and premedication with drugs are methods to allay the anxiety of the children in the perioperative period. ${ }^{3}$ \\ Among the various routes of premedication, intranasal route has come into practice from early nineties. 4,5 It is relatively a quick, painless with a high bioavailability. Most commonly used drug for premedication is Midazolam. Dexmedetomidine, an $\alpha 2$ agonist, is now becoming popular because of its excellent sedative, anxiolytic, sympatholytic and analgesic properties. $6,7,8$ \\ This study was conducted to compare the effects of Dexmedetomidine and Midazolam administered intranasally for premedication in children undergoing elective surgery under general anaesthesia.}

\#8, 5th Cross, $7^{\text {th }}$ Main Road,

Srinivasa Nagar, Vayaloor Road,

Trichy - 620017.

E-mail: dranitha81@gmail.com

DOI: $10.14260 /$ jemds $/ 2017 / 624$

\section{MATERIALS AND METHODS}

This study was conducted in Thanjavur Medical College Hospital from August 2011 to October 2013. 43 was the estimated sample size in each group. According to a study by Meenakshi Sundaram AL et al, ${ }^{9}$ at induction of anaesthesia, $24.7 \%$ and $67.4 \%$ of the children from groups $M$ and $D$ 
respectively were satisfactorily sedated with an allocation ratio of 1 , Alpha $=0.01$ and Beta $=0.10$. Finally, a total of 100 children scheduled for elective surgeries under General Anaesthesia were included, 50 in each group. Children meeting the following selection criteria were included in the study. Block randomisation technique was used to allocate the children to midazolam and dexmedetomidine group. Blocks of varying sizes ranging from $2-6$ used for block randomisation. Approval from Institutional Ethical Committee was obtained.

\section{Inclusion Criteria}

1. Children of both sexes aged 5-12 Yrs.,

2. Belonging to ASA I and II,

3. Weighing $<30 \mathrm{~kg}$,

4. Undergoing elective surgery under GA.

\section{Exclusion Criteria}

1. Known allergy or Hypersensitivity to Dexmedetomidine or Midazolam,

2. Organ dysfunction,

3. Cardiac arrhythmia,

4. Congenital heart disease,

5. Mental retardation,

6. Patient refusal,

7. H/o snoring or sleep apnoea,

8. Polyps and infections of nasal cavity.

\section{The Children were Divided into Two Groups-}

Group IN-D ( $\mathrm{n}=50)$ - Intranasal Dexmedetomidine.

Group IN-M ( $=50)$ - Intranasal Midazolam.

Children were kept nil per oral for 8 hours. Informed written consent was obtained from the parents. Children were randomly assigned to one of two groups. Baseline heart rate, systolic blood pressure and SPO2 were recorded.

Group IN-D received $1 \mu \mathrm{g} / \mathrm{kg}$ of intranasal dexmedetomidine and Group IN-M received $0.2 \mathrm{mg} / \mathrm{kg}$ of intranasal midazolam 60 minutes before induction.

The study drugs were prepared by an independent person using the intravenous preparations of dexmedetomidine $(100 \mu \mathrm{g} / \mathrm{kg})$ and midazolam $(5 \mathrm{mg} / \mathrm{mL})$. Intranasal medication was prepared in a 2-ml syringe and $0.9 \%$ saline was added to make a final volume of $1.5 \mathrm{~mL}$. The medication was administered in preoperative room in the presence of one parent (Preferably mother). The drug was dripped into the nostrils with the child in the recumbent position. Patients and the observer were blinded to the drug being administered.

Continuous heart rate and SPO2 monitoring done. Desaturation was managed with 02 supplementation through nasal mask. After 60 minutes the child was shifted to the operating table.

Sedation status was assessed during parental separation with a 6 - point sedation scale Modified from the Observer Assessment of Alertness and Sedation scale.

6 - Appears alert and awake, responds readily to name.

5 - Appears asleep, responds readily to name spoken in normal tone.

4 - Lethargic response to name spoken in normal tone.

3 - Respond only after name called loudly or repeatedly.

2 - Responds only to mild prodding or shaking.

1 - Does not respond to mild prodding or shaking.
Sedation score from 1 - 4 was considered satisfactory while score from $5-6$ was considered unsatisfactory.

Behaviour score during induction was assessed on the operating table by a 4 - point scale-

4 - Crying or resisting.

3 - Anxious and could not be reassured.

2 - Anxious but could be reassured.

1 - Calm and co-operative.

Behaviour score of 1 or 2 was considered satisfactory while 3 or 4 was considered unsatisfactory.

The acceptance of IV cannulation in the forearm of the child was graded as-

Grade 1 - Calm, co-operative, asleep - Good.

Grade 2 - Co-operative with reassurance - Moderate.

Grade 3 - Combative, crying - Poor.

Glycopyrrolate $10 \mu \mathrm{g} / \mathrm{kg}$, ondansetron $0.15 \mathrm{mg} / \mathrm{kg}$ were given IV preoxygenation done with $100 \% 02$ for 3 minutes with a scented facemask. Acceptance of facemask by the child was graded with the same grading as that of the acceptance of IV cannulation.

With standard monitoring, General Anaesthesia was administered. Recovery was good and the children were shifted to postoperative ward.

\section{Statistical Analysis}

The collected data were analysed by using GraphPad Instat 3.06 software according to variables for chi square test and student's t-test. The results are obtained in the form of range, mean and standard deviation. The probability value ' $p$ ' of less than 0.05 was considered statistically significant.

\section{RESULTS}

Patient's demographic data including age, sex and weight between two groups were comparable (table 1). The age distribution was in the range of $5-12$ years in both the groups. The mean age of group IN-D is 9.04 and group IN-M is 8.80. The mean weight of group IN - D was $23.36 \mathrm{~kg}$ and that of group IN-M was $23 \mathrm{~kg}$. The p value was $0.692(>0.05)$ was statistically not significant.

\begin{tabular}{|c|c|c|c|}
\hline Sl. No. & Data & Group IN - D & Group IN - M \\
\hline 1. & Age (Mean) & 9.04 & 8.80 \\
\hline 2. & Weight in Kgs. (Mean) & 23.36 & 23 \\
\hline 3. & $\begin{array}{c}\text { Sex } \\
\text { Male } \\
\text { Female }\end{array}$ & $\begin{array}{l}22 \\
28\end{array}$ & $\begin{array}{l}24 \\
26\end{array}$ \\
\hline & Table 1. & c Data & \\
\hline
\end{tabular}

\begin{tabular}{|c|c|c|c|c|}
\hline \multirow{2}{*}{ Parameter } & \multicolumn{2}{|c|}{ Age in years } & Weight in kilograms \\
\cline { 2 - 5 } & $\begin{array}{c}\text { Group } \\
\text { IN - D } \\
(\mathbf{n}=\mathbf{5 0})\end{array}$ & $\begin{array}{c}\text { Group } \\
\text { IN - M } \\
(\mathbf{n}=\mathbf{5 0})\end{array}$ & $\begin{array}{c}\text { Group } \\
\text { IN }- \text { D } \\
(\mathbf{n}=\mathbf{5 0})\end{array}$ & $\begin{array}{c}\text { Group } \\
\text { IN }- \text { M } \\
(\mathbf{n}=\mathbf{5 0})\end{array}$ \\
\hline Range & $5-12$ & $5-12$ & $14-30$ & $13-30$ \\
\hline Mean & 9.04 & 8.80 & 23.36 & 23 \\
\hline S.D. & 1.795 & 1.807 & 4.434 & 4.625 \\
\hline 'p' value & $0.4227(>0.05)$ & \multicolumn{2}{c|}{$0.692(>0.05)$} \\
\hline \multicolumn{4}{|c|}{ Table 2. Age and Weight Distribution } \\
\hline
\end{tabular}


Group Wise Distribution of Age, Weight and Sex

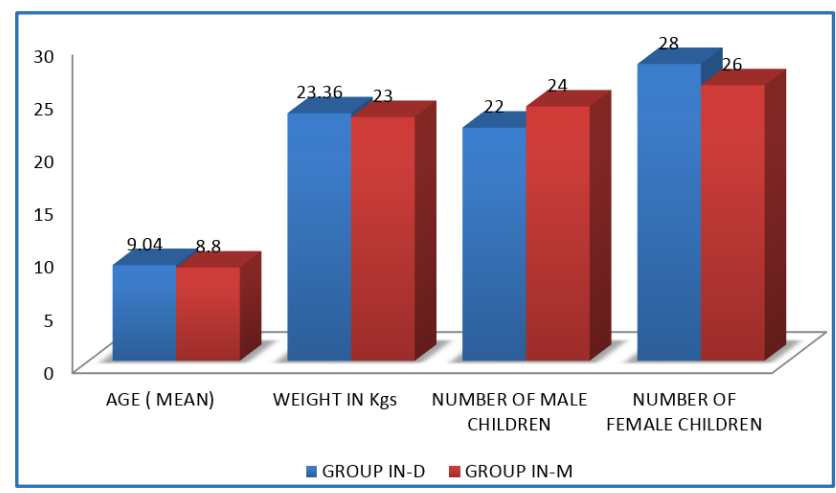

Figure 1. Shows the Distribution of Age, Weight and Sex in the Two Groups

The mean sedation score in group IN-D was 3.24 and in group IN-M was 4.32 . Sedation score at parental separation was satisfactory in $88 \%$ ( 44 children) of the group IN-D and in $60 \%$ (30 children) of the group IN-M. It was found to be unsatisfactory in $12 \%$ ( 6 children) of the group IN-D and in $40 \%$ ( 20 children) of the IN-M group. The ' $p$ ' value was 0.030 $(<0.05)$ which was statistically significant.

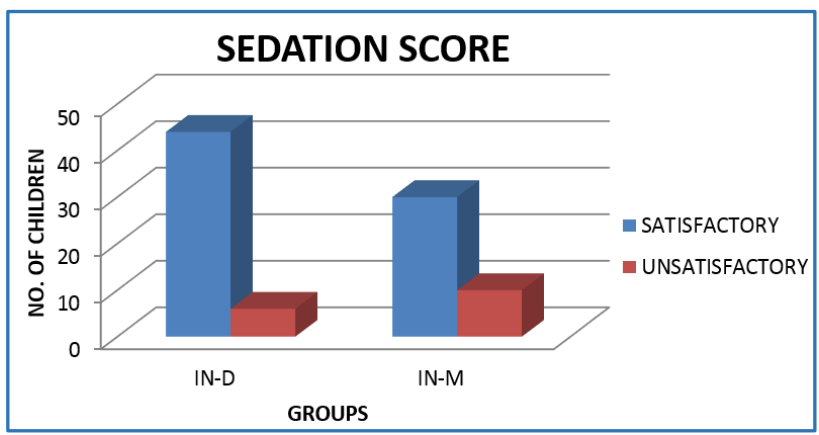

Figure 2. Shows the Distribution of

Sedation Score among the Two Groups

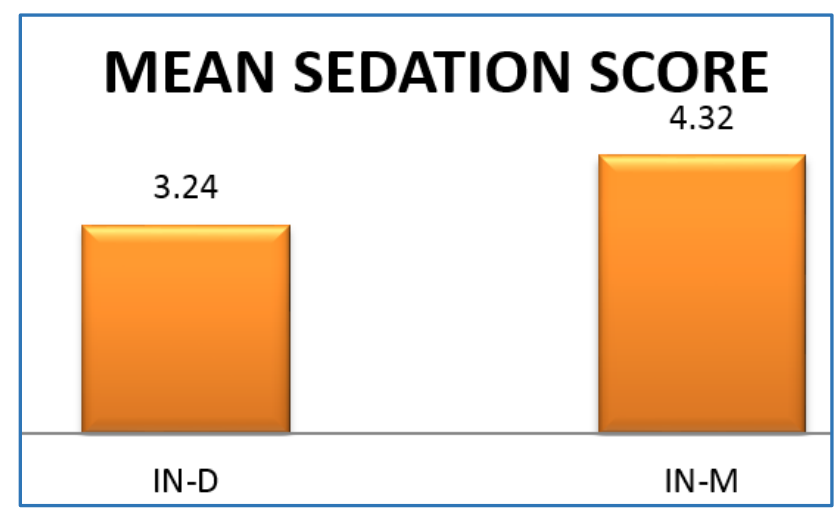

Figure 3. Shows the Mean Sedation Score in the Two Groups

The behaviour score in the operating table was satisfactory in 88\% (44 children) of group IN-D and 92\% (46 children) of group IN-M. It was unsatisfactory in $12 \%$ (6 children) of group IN-D and in $8 \%$ ( 4 children) in group IN M. The ' $p$ ' value was $0.738(>0.05)$ which was statistically not significant.



Figure 4. Shows the Distribution of Behaviour Score among the Two Groups

The table 3 shows the distribution of acceptance of IV cannulation between two groups. The grading was good in $36 \%$, moderate in $56 \%$ and poor in $8 \%$ of the children in both the groups.

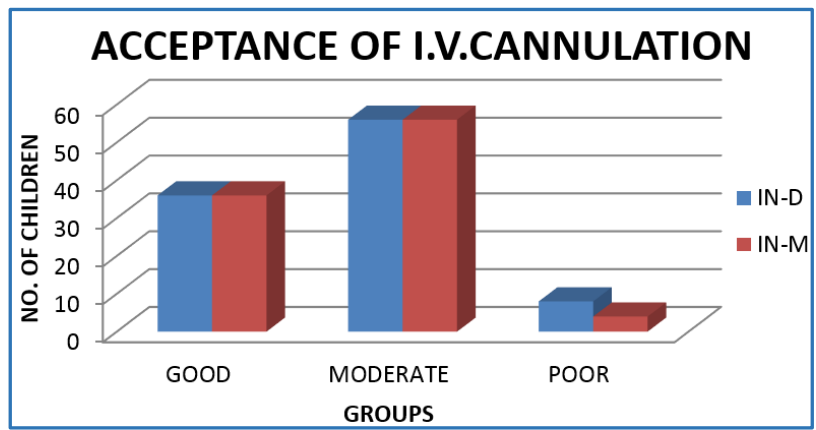

Figure 5. Shows the Distribution of Acceptance of IV Cannulation among the Two Groups

Acceptance of facemask was good in $68 \%$ of the children in group IN-D and in $60 \%$ of the children in group IN-M. Only two children (4\%) in group IN-D had a poor acceptance of facemask ('p' $=0.401)$.

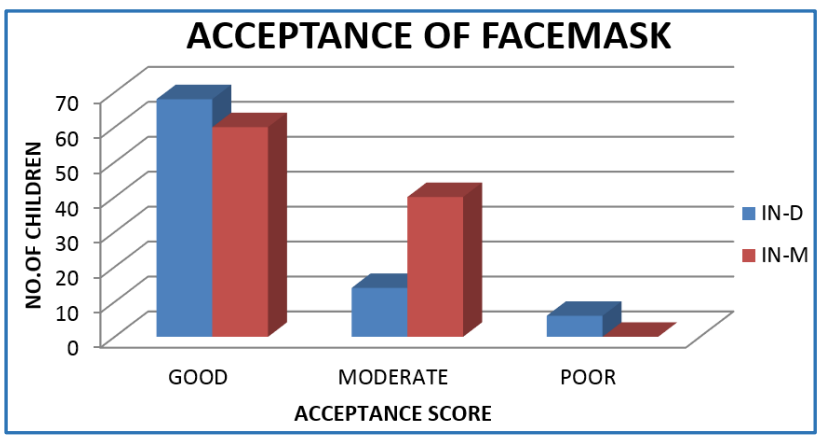

Figure 6. Shows the Distribution of Acceptance of Facemask among the Two Groups

\begin{tabular}{|c|c|c|c|c|c|}
\hline $\begin{array}{l}\text { Sl. } \\
\text { No. }\end{array}$ & Observation & $\begin{array}{c}\text { Group } \\
\text { IN-D } \\
(n=50)\end{array}$ & $\begin{array}{c}\text { Group } \\
\text { IN-M } \\
(n=\mathbf{5 0})\end{array}$ & $\begin{array}{c}\text { 'p' } \\
\text { value }\end{array}$ & $\begin{array}{c}\text { Statistical } \\
\text { Analysis }\end{array}$ \\
\hline 1. & $\begin{array}{l}\text { Sedation Score } \\
\text { at Parental } \\
\text { Separation } \\
\text { Satisfactory } \\
\text { Unsatisfactory }\end{array}$ & $\begin{array}{l}88 \% \\
12 \%\end{array}$ & $\begin{array}{l}60 \% \\
40 \%\end{array}$ & 0.030 & $\begin{array}{c}\text { Statistically } \\
\text { Significant } \\
(\mathrm{p}<0.05)\end{array}$ \\
\hline 2. & $\begin{array}{l}\text { Mean Sedation } \\
\text { Score }\end{array}$ & 3.24 & 4.32 & - & - \\
\hline
\end{tabular}




\begin{tabular}{|c|c|c|c|c|c|}
\hline 3. & $\begin{array}{c}\text { Behaviour } \\
\text { Score } \\
\text { Satisfactory } \\
\text { Unsatisfactory }\end{array}$ & $\begin{array}{l}88 \% \\
12 \%\end{array}$ & $\begin{array}{c}92 \% \\
8 \%\end{array}$ & 0.738 & $\begin{array}{c}\text { Statistically } \\
\text { not } \\
\text { significant }\end{array}$ \\
\hline 4. & $\begin{array}{c}\text { Acceptance of } \\
\text { IV Cannulation } \\
\text { Good } \\
\text { Moderate } \\
\text { Poor }\end{array}$ & $\begin{array}{c}36 \% \\
56 \% \\
8 \%\end{array}$ & $\begin{array}{c}36 \% \\
56 \% \\
8 \%\end{array}$ & 1.000 & $\begin{array}{l}\text { Statistically } \\
\text { not } \\
\text { significant }\end{array}$ \\
\hline 5. & $\begin{array}{c}\text { Acceptance of } \\
\text { Facemask } \\
\text { Good } \\
\text { Moderate } \\
\text { Poor }\end{array}$ & $\begin{array}{c}68 \% \\
28 \% \\
4 \%\end{array}$ & $\begin{array}{c}60 \% \\
40 \% \\
0 \%\end{array}$ & 0.401 & $\begin{array}{c}\text { Statistically } \\
\text { not } \\
\text { significant }\end{array}$ \\
\hline \multicolumn{6}{|c|}{ Table 3. Summary of the Results } \\
\hline
\end{tabular}

Continuous heart rate and SPO2 monitored, none of the children in either of the groups attained significant bradycardia and desaturation $(<95 \%)$. No subjective adverse effects were observed in group IN-D. Three children complained of nasal irritation and child had paradoxical excitation in group IN-M following drug administration. These parameters were not statistically analysed as our study was not designed to investigate these parameters.

\section{DISCUSSION}

Selecting appropriate premedication in safe yet effective doses is a primary responsibility of an anaesthesiologist. Facilitating an anxiety free separation and a smooth induction are the primary goals of premedicant drug administration. Analgesia, amnesia, and prevention of physiologic stress are other beneficial effects of pharmacological intervention. The main drawback of premedication particularly in children is that the process of administering the medication may actually increase anxiety. A child's major fear associated with hospitalisation is fear from needles and injections. Thus, a non-invasive route is generally preferred.

Various routes for premedication in children have been formulated keeping in mind the specific problems of the paediatric age group. Intranasal route is a rapid and effective way of administering premedication in children. Among the non-invasive routes, it has gained importance in recent decades. It provides a direct route into the systemic circulation for drugs that easily cross mucous membranes. Importantly the first bypass metabolism is circumvented and the bioavailability is better than other routes. For many intranasal medications, the rates of absorption and plasma concentrations are comparable to intravenous administration and are typically better than subcutaneous or intramuscular routes. Oral route is poorly accepted and rectal route is less ideal especially for older children.

Alpha - 2 agonists are assuming greater importance as anaesthetic adjuvants and analgesics.10,11 Dexmedetomidine is a highly selective, specific and potent alpha - 2 adrenoceptor. It was introduced in United States and had been in clinical practice since 1999. Sedative - hypnotic effects are produced by the action on alpha - 2 receptors in the locus coeruleus. Analgesic effect is produced by its action on alpha - 2 receptors within the locus coeruleus and within the spinal cord. Despite effective sedation there is limited respiratory depression. Following intranasal administration,
$1 \mu \mathrm{g} / \mathrm{kg}$ has an onset time of 45 minutes with a peak effect at $60-105$ minutes in healthy adults. Bioavailability of intranasal dexmedetomidine is $65 \%$ (35-93\%). ${ }^{12}$ Whereas the sedation, anterograde amnesia and anticonvulsant properties of midazolam are mediated via alpha 1 GABA receptors. These receptors are found in highest densities in the olfactory bulb, cerebral cortex, cerebellum, hippocampus, substantia nigra and inferior colliculus.

Among the large percentage of paediatric patients, anaesthesia induction was known to be the anxiety provoking part. Awake intravenous cannulation and parental separation were more vulnerable points. So this study was designed to compare the efficacy of intranasal dexmedetomidine and midazolam with respect to sedation status at parental separation, behaviour level inside the operating room, acceptance of IV cannulation and acceptance of facemask during induction.

Several studies had used intranasal midazolam and the possibility of neurotoxicity occurred only after chronic administration through intrathecal route. ${ }^{13}$ Timolirola et al ${ }^{12}$ showed intranasal dexmedetomidine does not produce local effects on nasal mucosa like mucosal irritation, ulceration, inflammation and bleeding. Pradiptabhakta et al ${ }^{14}$ in their study concluded that intranasal midazolam in a dose of 0.2 $\mathrm{mg} / \mathrm{kg}$ was as effective as $0.3 \mathrm{mg} / \mathrm{kg}$ in producing anxiolysis and sedation. Yuen et al ${ }^{15}$ observed that $1 \mu \mathrm{g} / \mathrm{kg}$ dexmedetomidine produced significant and satisfactory sedation at parental separation and at induction. Aynur et al ${ }^{16}$ compared the efficacy of $1 \mu \mathrm{g} / \mathrm{kg}$ of dexmedetomidine and 0.2 $\mathrm{mg} / \mathrm{kg}$ of midazolam administered intranasally as premedication agents in children between 2-9 years.

The sedation produced by dexmedetomidine significantly differs when compared with other drugs that act through GABA systems. ${ }^{15}$ Among the 50 children, 22 children (88\%) in group IN-D and 15 children (60\%) in group IN-M attained a significant and satisfactory sedation status at parental separation at 60 minutes $(p=0.030)$. While Aynur akin et al ${ }^{16}$ showed that $79.9 \%$ in group D and $95.5 \%$ in group $M$ attained satisfactory sedation ( 45 minutes). The peak effect of intranasal midazolam is $10-15$ minutes and duration of action is $30-60$ minutes. In this study, the sedation status was assessed at 60 minutes, so only $60 \%$ in group IN-M was found with satisfactory sedation. The mean sedation score in group IN-D was $3.24 \pm 0.959$ and in group IN-M was $4.32 \pm 0.748$ $(\mathrm{p}=0.001)$.

The behaviour level of the children was assessed with a four point scale. $88 \%$ of children in group IN-D and $92 \%$ in group IN-M attained satisfactory behaviour score (score 1 or 2 ). None of the children in either groups had worst and unsatisfactory behaviour (score 4). 3 children (12\%) in group IN-D and $2(8 \%)$ in group IN-M had score 3 (Anxious, not reassured). Yuen et $\mathrm{al}^{15}$ in their study also showed that children in groups $\mathrm{M}, \mathrm{D}-0.5$ and D-1 premedicated with midazolam $(0.5 \mathrm{mg} / \mathrm{kg})$ and dexmedetomidine $(0.5$ and 1 $\mu \mathrm{g} / \mathrm{kg}$ ) had comparable behaviour level. There was a tendency of the children in groups D-0.5 and D- 1 having unsatisfactory behaviour after shifting to operating room. But still there were no statistically significant differences when compared to group M.

Children usually have an aversion for needles. If acceptance of the IV cannulation is good enough, it indirectly counterchecks the sedation status and behaviour level. The 
children in both groups IN-D and IN-M had similar acceptance of IV cannulation ( $p=1.000)$.

The acceptance of facemask was good (score 1) in $68 \%$ of the children in group IN-D and in $60 \%$ of the children in group IN-M. It was found to be moderate (score 2) in $28 \%$ of the children in group IN-D and in $40 \%$ of the children in group IN-M. 2 children (4\%) in group IN-D had a poor (score $3)$ acceptance of facemask ( $p=0.401)$.

\section{Limitations of the Study}

This study was conducted entirely in the preoperative period, the intraoperative and the postoperative effects were not evaluated.

In summary, we found that intranasal administration of dexmedetomidine $1 \mu \mathrm{g} / \mathrm{kg}$ for premedication in children undergoing elective surgery provides significant and satisfactory sedation $\left({ }^{\prime} p^{\prime}=0.030\right)$. However, intranasal midazolam was as effective as dexmedetomidine in providing satisfactory behaviour level inside the operating room. Both the intranasal premedicants were equally effective in providing satisfactory conditions for acceptance of IV cannulation and acceptance of facemask during induction.

\section{CONCLUSION}

Intranasal premedication allows an effective and predictable sedation in children. Both midazolam and dexmedetomidine produce a good level of sedation, behaviour and acceptable levels for IV cannulation and face mask acceptance during induction. But the quality of sedation is significantly better in dexmedetomidine group.

\section{REFERENCES}

[1] Kain ZN, Mayes LC. Anxiety in children during the perioperative period: In: Bornstein $\mathrm{MH}$, Genevro JL. eds. Child development and behavioral pediatrics. Mahwah, NJ, US: Lawrence Erlbaum Associates Publishers 1996:85-103.

[2] Kain ZN. Perioperative psychological trauma in children. Complications in Anaesthesia. $1^{\text {st }}$ edn. Philadelphia: WB Saunders 1990.

[3] Messeri A, Caprilli S, Busoni P. Anaesthesia induction in children: a psychological evaluation of the efficiency of parent's presence. Pediatric Anaesthesia 2004;14(7):551-6.

[4] Wilton NCT, Leigh J, Rosen DR, et al. Preanaesthetic sedation of preschool children using intranasal midazolam. Anaesthesiology 1988;69(6):972-5.
[5] Davis PJ, Tome JA, McGowan FX, et al. Preanaesthetic medication with intranasal midazolam for very brief pediatric surgical procedures. Effect on recovery and hospital discharge times. Anaesthesiology 1995;82(1): 2-5.

[6] Schmidt AP, Valinetti EA, Banderira D, et al. Effects of preanaesthetic administration of midazolam, clonidine or dexmedetomidine on postoperative pain and anxiety in children. Paediatr Anaesth 2007;17(7):66774.

[7] Yuen VM, Irwin MG, Hui TW, et al. A double blind crossover assessment of the sedative and analgesic effects of intranasal dexmedetomidine. Anesth Analg 2007;105(2):374-80.

[8] Khan ZP, Ferguson CN, Jones RM. Alpha-2 and imidazoline receptor agonists. Their pharmacology and therapeutic role. Anaesthesia 1999;54(2):146-65.

[9] MeenakshiSundaram AL, Mathian VM. Comparative evaluation of intranasal dexmedetomidine and intranasal midazolam for premedication in children: a double blind randomised controlled trial. Journal of Indian Dental Association 2011;5(7):777-81.

[10] Sudheesh K, Harsoor S. Dexmedetomidine in anaesthesia practice: a wonder drug? Indian J Anaesth 2011;55(4):323-4.

[11] Afonso J, Reis F. Dexmedetomidine: current role in anaesthesia and intensive care. Rev Bras Anaestesiol 2012;62(1):118-33.

[12] Lirola T, Vilo S, Manner T, et al. Bioavailability of dexmedetomidine after intranasal administration. European Journal of Clinical Pharmacology 2011;67(8):825-31.

[13] Wang J, Bu G. Influence of intranasal midazolam on structure of nasal mucosa. Zhonghusa Er Bi Yan HouKeZaZhi 1999;34(1):14-5.

[14] Bhakta P, Ghosh BR, Roy M, et al. Evaluation of intranasal midazolam for preanaesthetic sedation in pediatric patients: Indian Journal of Anaesthesia 2007;51(2):111-116.

[15] Yuen VM, Hui TM, Irwin MG, et al. A comparison of intranasal dexmedetomidine and oral midazolam for premedication in pediatric anaesthesia: a doubleblinded randomized controlled trial. Anesth Analg 2008:106(6):1715-21.

[16] Akin A, Bayram A, Esmaoglu A, et al. Dexmedetomidine vs. midazolam for premedication of pediatric patients undergoing anesthesia. Paediatric Anaesthesia 2012;22(9):871-6. 